\title{
Blow Flies Visiting Decaying Alligators: Is Succession Synchronous or Asynchronous?
}

\author{
Mark P. Nelder, ${ }^{1,2}$ John W. McCreadie, ${ }^{1}$ and Clinton S. Major ${ }^{1}$ \\ ${ }^{1}$ Department of Biology, University of South Alabama, Life Sciences Building, Room 124, 307 University Boulevard, \\ Mobile, AL 36688, USA \\ ${ }^{2}$ Center for Vector Biology, Department of Entomology, Rutgers University-School of Environmental and Biological Sciences, \\ 180 Jones Avenue, New Brunswick, NJ 08901, USA
}

Correspondence should be addressed to Mark P. Nelder, mnelder@rci.rutgers.edu

Received 12 May 2008; Revised 27 August 2008; Accepted 15 September 2008

Recommended by Martin H. Villet

\begin{abstract}
Succession patterns of adult blow flies (Diptera: Calliphoridae) on decaying alligators were investigated in Mobile (Ala, USA) during August 2002. The most abundant blow fly species visiting the carcasses were Chrysomya rufifacies (Macquart), Cochliomyia macellaria (Fabricus), Chrysomya megacephala (Fabricus), Phormia regina (Meigen), and Lucilia coeruleiviridis (Macquart). Lucilia coeruleiviridis was collected more often during the early stages of decomposition, followed by Chrysomya spp., Cochliomyia macellaria, and Phormia regina in the later stages. Lucilia coeruleiviridis was the only synchronous blow fly on the three carcasses; other blow fly species exhibited only site-specific synchrony. Using dichotomous correlations and analyses of variance, we demonstrated that blow fly-community succession was asynchronous among three alligators; however, Monte Carlo simulations indicate that there was some degree of synchrony between the carcasses.
\end{abstract}

Copyright (C) 2009 Mark P. Nelder et al. This is an open access article distributed under the Creative Commons Attribution License, which permits unrestricted use, distribution, and reproduction in any medium, provided the original work is properly cited.

\section{Introduction}

Blow flies (Diptera; Calliphoridae) are ubiquitous insects during the early stages of animal decay and their larvae are important in estimating the time since death or the postmortem interval (PMI) of a carcass [1]. Larval age of the earliest carrion-arriving blow fly species can be estimated based on data developed from controlled carrion studies $[2,3]$. Faunal composition (succession data) of carrion can be predicted for a given area under specific conditions and the composition compared to baseline data obtained from an animal model [4-8].

Insect succession on carrion has been examined in detail in the southeastern United States. Studies have been performed on decaying dogs, Canis lupus L., in Tennessee [9]; pigs, Sus scrofa L., in South Carolina [10] and Florida [11]; humans, Homo sapiens L., in Tennessee [12]; rats, Rattus rattus L., in South Carolina [13]; and a variety of vertebrate species in North Carolina [14], Mississippi [15], and Louisiana [16]. There have been few published reports on the subject from Alabama and Georgia, however, are needed for better understanding of blow fly ecology associated with carrion.

Variation associated with blow fly succession on carcasses placed in the same habitat at the same time has not been tested. Hence, this raises the question of whether carcasses placed simultaneously in the same habitat decompose in the same manner and whether all carcasses experience the same blow fly-succession pattern. To test these hypotheses, we simultaneously placed three carcasses in the field and compared the succession of blow flies on each carcass. Specifically, we tested if the pattern or synchrony of calliphorid succession varied among carcasses.

\section{Materials and Methods}

2.1. Study Area. Sites were located in an evergreen woodlot on the campus of the University of South Alabama, inside the city limits of Mobile, Alabama. The woodlot was dominated by a mixture of pines (loblolly, Pinus taeda L., and longleaf, 
Pinus palustris Miller) and hardwoods typical of forests occurring on upland areas associated with sandy loam soils. The canopy was mostly closed with two of three sites in this forest having greater than $75 \%$ cover; site C had less than 50\% canopy cover. Oaks present included sand, Quercus geminata Small; southern red, Quercus falcata Michaux; turkey, Quercus laevis Walter; and water, Quercus nigra L. Other hardwoods included American witch-hazel, Hamamelis virginiana L.; flowering dogwood, Cornus florida L.; red maple, Acer rubrum L.; and southern magnolia, Magnolia grandiflora $\mathrm{L}$. The magnolia and maple extended up to the bottom of the pine canopy and form a patchy subcanopy. Shrubs in the woodlot included American holly, Ilex opaca Aiton; several azalea species, Rhododendron spp.; devilwood, Osmanthus americana (L.); swamp titi, Cyrilla racemiflora L.; large gallberry, Ilex coriacea (Pursh); and sparkleberry, Vaccinium arboreum Marshall. The floor was sparse with occasional patches of herbaceous growth occurring in small openings. Herbaceous species were dominated by downy danthonia, Danthonia sericea Nuttall; fourleaf yam, Dioscorea villosa L.; flowering spurge, Euphorbia corollata L.; greater tickseed, Coreopsis major Walter; longleaf woodoats, Chasmanthium sessiliflorum (Poiret); a sedge, undetermined; St. Andrew's cross, Hypericum hypericoides (L.); strawberry bush, Euonymus americanus L.; and wood spurge, Euphorbia commutatus Engelmann. Vines were abundant at each site and included Carolina jasmine, Gelsemium sempervirens (L.); catbrier, Smilax bona-nox L.; cat greenbrier, Smilax glauca Walter; crossvine, Bignonia capreolata (L.); and muscadine, Vitis rotundifolia Michaux. This woodlot is typical of forests that have established on former mesic to dry-mesic longleaf pine sites following removal of longleaf pine.

2.2. Sampling Protocol. The American alligator, Alligator mississippiensis Daudin, was chosen as the model carcass because they were readily available as fresh-frozen (frozen since May 2002) specimens and relatively little is known about blow fly succession on these animals $[16,17]$. Specimens used were accidentally trapped during turtle surveys in the MobileTensaw delta in southwestern Alabama. Dead alligators were sealed in black garbage bags at collection time and frozen at $-20^{\circ} \mathrm{C}$ until needed. Approximately 24 hours before the beginning of the study, the carcasses were placed in a walk in refrigerator at $4^{\circ} \mathrm{C}$ to thaw slowly. Alligator sizes were as follows: site A: $1.65 \mathrm{~m}, 17.9 \mathrm{~kg}$; site $\mathrm{B}: 1.68 \mathrm{~m}, 20.0 \mathrm{~kg}$; and site C: $1.78 \mathrm{~m}, 24.3 \mathrm{~kg}$. Each alligator was placed in a stainless-steel wire cage $(1.8 \times 0.35 \times 0.25 \mathrm{~m}$; mesh size $=$ $2.5 \times 2.5 \mathrm{~cm})$ to prevent carcass disturbance by vertebrate scavengers and cage placed in the woodlot 5 August 2002 at 1000 hours (i.e., day zero). For purposes of this study, calliphorid collection was ceased on 15 August 2002. Cages were arranged along a single transect, $50 \mathrm{~m}$ apart.

The decomposition of each alligator was divided into stages following those of Reed [9] and Johnson [18]. The beginning and end of these stages were difficult to discern and we only report approximate time intervals of the stages. It is important to note that these stages are part of a continuum and not categorical; they are used as reference points to compare the physical decomposition of the carcasses and are considered arbitrary in terms of blow fly succession $[10,19,20]$.

Sticky fly-paper was used to collect adult blow flies arriving at the carcasses. Two strips of sticky fly paper $(120 \mathrm{~cm} \times 4 \mathrm{~cm})$ were placed on top of each cage at 1000 hours daily. After 24 hours, the fly paper was removed and placed in a labeled container with $95 \%$ ethanol and new fly paper replaced on cage. Blow flies were later removed from the sticky paper, identified, and returned to alcohol-labeled vials. To supplement sticky-paper collections, aerial netting was performed over the cages ( 5 minutes per cage). Blow flies collected by aerial netting were killed in the field using a collecting jar laced with ethyl acetate, placed in labeled vials, and later pinned in the laboratory. Identifications were made according to Hall [21], Hall and Townsend [22], Dear [23], and Whitworth [24].

Blow fly larvae were collected daily from different areas on each carcass and the surrounding ground. Larvae were placed in plastic containers and transported back to the laboratory. One-half of the larvae from each carcass were preserved by boiling in water and then placing them in Kahle's solution [25]. The remaining larvae were reared to adults using the following procedure. Larvae $(N=3-5$ per container) were placed on a small piece of raw calf liver (approximately $10 \mathrm{~g}$ ) and then wrapped in moist paper towel. A $3 \mathrm{~cm}$ layer of vermiculite was added to $150 \mathrm{~mL}$ clearplastic containers; larvae and liver, wrapped in paper towel, were placed on top of the vermiculite. Pieces of cardboard, furnished with small holes for air circulation, were used to cover containers. Containers were held at room temperature (i.e., $22-24^{\circ} \mathrm{C}$ ) with a light: dark regime of $12: 12$ hours. Containers were inspected twice daily for the presence of adult blow flies.

As the condition of some flies from the sticky-paper were unsuitable for identification, only adult flies that contained all relevant taxonomic characters were included in analyses. It was assumed that damaged specimens would occur in roughly equal proportions among blow fly species. Reared larvae were used to confirm the identity of sticky-paper collected adult blow flies. Lucilia cluvia (Walker), Lucilia eximia (Wiedemann), and Lucilia sericata (Meigen) were collected as adults on the sticky paper and were not reared from larvae found on the carcasses. Voucher specimens have been deposited in the University of South Alabama's Arthropod Depository.

2.3. Statistical Analyses. All statistical tests were considered significant at $P<.05$, and the experiment-wise rate was adjusted for each correlation to maintain a family error rate of $P=.05$. For each treatment, an experiment-wise adjustment of $P$-values was made to preserve a family error rate of $P=.05$. For each species of blow fly, a dichotomous (present/absent) correlation was used to determine the degree of temporal association among each site. Hence, for each species, three correlations were calculated, that is, site $A$ versus site $B$, site $A$ versus site $C$, and site $B$ versus site 
TABLE 1: Blow fly succession on site A’s decaying alligator, Mobile, Ala, USA (August 2002).

\begin{tabular}{|c|c|c|c|c|c|c|c|c|c|c|}
\hline \multirow{3}{*}{ Blow fly species } & \multicolumn{10}{|c|}{ Daily abundance ${ }^{\mathrm{a}, \mathrm{b}}$ (decomposition stage) } \\
\hline & 1 & 2 & 3 & 4 & 5 & 6 & 7 & 8 & 9 & 10 \\
\hline & Fresh & Bloat & Active & & & & & & & \\
\hline Chrysomya rufifacies & + & - & + & + & +++ & ++ & +++ & ++++ & ++ & + \\
\hline Cochliomyia macellaria & - & - & + & ++ & +++ & ++ & ++ & ++ & + & - \\
\hline Chrysomya megacephala & - & - & + & ++ & ++ & +++ & ++ & ++ & + & - \\
\hline Phormia regina & - & - & - & + & ++ & ++ & + & - & + & - \\
\hline Lucilia coeruleiviridis & + & + & + & + & - & - & - & - & - & - \\
\hline
\end{tabular}

"“-” 0 adults collected, “+” $1-5$, “++” =6-15, “+++” = 16-25, “++++” > 26.

${ }^{b}$ Day 1 represents the first 24 hours of the study; this 24 -hour period began at hour zero (i.e., the time of placement of the carcass in the field at 1000 hours on 5 August 2002) till 1000 hours the next morning on 6 August 2002.

C. As these correlations were special cases of the Pearsonproduct-moment-correlation coefficient, a $z$ test was used to determine significance [26]. To determine if the relative abundance of each species of blow fly collected on the fly paper differed among sites, an analysis of variance (ANOVA) was used, with number of flies for each species as the response variable, site as the main effect, and day as the block (random variable). For significant main effects, differences among means were determined using the Tukey multiple comparison procedure [27]. All data was normalized before statistical tests.

A Monte Carlo approach was used to examine the similarity of community succession among the three sites used in this study. The intent here was to determine if combined-species occurrence for all species of blow flies, among all sites, occurred at a frequency different from that expected by a random model. Combined species cooccurrence (i.e., the number of times a species occurs on the same day at any pair of sites, summed for all species in the analyses) at a frequency greater than that expected by a random model would indicate predictable community succession among sites [28]. In contrast to correlation or ANOVA analyses, all species were considered simultaneously in this procedure. Our observed test statistic was the total number of co-occurrences for all species. For example, if a particular species occurred at sites A and B on the same five days, site $\mathrm{B}$ and $\mathrm{C}$ on the same four days, and sites $\mathrm{A}$ and $\mathrm{C}$ on the same six days, then the total number of observed cooccurrences among sites for that species would be 15. Adding the number of co-occurrences for all five species of blow flies considered in our study produces the observed test statistic.

The Monte Carlo procedure allows the probability distribution for the test statistic (in our case, the number of times a species occurs on the same day at any pair of sites, summed for all species in the analyses) to be generated while permitting the incorporation of relevant biological constraints into the model used to generate the test-statistic distribution $[29,30]$. The constraint used in generating our test statistic distribution was that the frequency of each species' occurrence, at each site, was equal to the observed frequency for that species at that site. The test statistic distribution was generated using 1000 Monte Carlo simulations [29] and the observed number of total co-occurrences was then compared with the generated distribution, and if the $P$ value of the observed co-occurrence was low (i.e., $P<.05$ ), then the observation was judged to be significant.

\section{Results}

Climatological data was obtained from a weather station located $6.5 \mathrm{~km}$ from the study sites. The mean daily temperature during this study (5-15 August 2002) was $26.8 \pm 0.5^{\circ} \mathrm{C}$ with a mean daily high of $31.2 \pm 0.9^{\circ} \mathrm{C}$ and a mean daily low of $22.8 \pm 0.5^{\circ} \mathrm{C}$. Rainfall was limited to a total of $7.5 \mathrm{~cm}$ during the study, most $(5.2 \mathrm{~cm})$ of the precipitation occurred during the first 24 hours.

Eight species of Calliphoridae were identified from decaying alligators during this study; Chrysomya rufifacies (Macquart) ( $N=253,31.6 \%$ of total 806 blow flies), Cochliomyia macellaria (Fabricius) $(N=216,27.0 \%)$, Chrysomya megacephala (Fabricius) $(N=148,18.5 \%)$, Phormia regina (Meigen) $(N=100,12.5 \%)$, Lucilia coeruleiviridis $(N=80,10 \%)$, Lucilia cluvia $(N=4,0.5 \%)$, Lucilia eximia $(N=4,0.5 \%)$, and Lucilia sericata $(N=1$, $0.1 \%)$. Daily relative abundances of adult blow flies at each carcass and stage of decomposition are presented in Tables 1,2 , and 3. The fresh stage began at time zero and ended approximately at 24 hours. Lucilia coeruleiviridis was the most prevalent blow fly active about the carcasses in the first 24 hours, ovipositing in and around the eyes, mouth, and nostrils. Lucilia coeruleiviridis were noted ovipositing on the carcasses within 15 minutes of being placed in field. At the time of this oviposition, it was not raining.

The bloat stage lasted 1-3 days depending on the site. By the end of this stage, at sites A and B, larval masses enveloped the head and limb-torso junctions. At site $\mathrm{C}$, decomposition was slower with maggot masses restricted to the head. The majority of flies visiting the carcasses during this stage were Lucilia coeruleiviridis (Tables 1-3). Blow flies encountered in very low numbers during this stage were Lucilia cluvia $(N=$ 4, site B, day 2), Lucilia eximia $(N=3$, site B, day $2 ; N=1$, site $\mathrm{A}$, day 3$)$, and Lucilia sericata $(N=1$, site $\mathrm{B}$, day 2$)$.

The decay stage started approximately (depending on site) at 72 hours and ended after approximately day 10 . Larval masses had spread out from the head and limbtorso junctions and were consuming decaying flesh in an 
TABLE 2: Blow fly succession on site B’s decaying alligator, Mobile, Ala, USA (August 2002).

\begin{tabular}{|c|c|c|c|c|c|c|c|c|c|c|}
\hline \multirow{3}{*}{ Blow fly species } & \multicolumn{10}{|c|}{ Daily abundance ${ }^{\mathrm{a}, \mathrm{b}}$ (decomposition stage) } \\
\hline & 1 & 2 & 3 & 4 & 5 & 6 & 7 & 8 & 9 & 10 \\
\hline & Fresh & Bloat & & Active & & & & & & \\
\hline Chrysomya rufifacies & - & - & - & ++ & ++++ & + & + & + & + & +++ \\
\hline Cochliomyia macellaria & - & - & + & ++ & +++ & + & + & + & + & - \\
\hline Chrysomya megacephala & - & + & + & +++ & - & + & - & + & - & - \\
\hline Phormia regina & - & - & - & ++ & ++ & + & + & - & - & + \\
\hline Lucilia coeruleiviridis & + & + & + & + & - & - & + & - & - & - \\
\hline
\end{tabular}

a " - " $=0$ adults collected, " + " $1-5$, , $++"=6-15$, , $+++"=16-25$, , $++++">26$.

${ }^{b}$ Day 1 represents the first 24 hours of the study; this 24 -hour period began at hour zero (i.e., the time of placement of the carcass in the field at 1000 hours on 5 August 2002) till 1000 hours the next morning on 6 August 2002.

TABle 3: Blow fly succession on site C's decaying alligator, Mobile, Ala, USA (August 2002).

\begin{tabular}{|c|c|c|c|c|c|c|c|c|c|c|}
\hline \multirow{3}{*}{ Blow fly species } & \multicolumn{10}{|c|}{ Daily abundance ${ }^{\mathrm{a}, \mathrm{b}}$ (decomposition stage) } \\
\hline & 1 & 2 & 3 & 4 & 5 & 6 & 7 & 8 & 9 & 10 \\
\hline & Fresh & Bloat & & & Active & & & & & \\
\hline Chrysomya rufifacies & - & - & - & - & +++ & ++ & +++ & ++++ & - & - \\
\hline Cochliomyia macellaria & - & + & - & ++ & ++++ & ++ & ++ & ++ & - & - \\
\hline Chrysomya megacephala & - & - & - & ++ & ++ & ++ & ++ & ++ & - & - \\
\hline Phormia regina & - & - & - & + & +++ & +++ & ++ & + & + & - \\
\hline Lucilia coeruleiviridis & + & ++ & +++ & ++ & - & - & - & - & - & - \\
\hline
\end{tabular}

${ }^{b}$ Day 1 represents the first 24 hours of the study; this 24 -hour period began at hour zero (i.e., the time of placement of the carcass in the field at 1000 hours on 5 August 2002) till 1000 hours the next morning on 6 August 2002.

anterior-to-posterior fashion. The last part of the alligator to be consumed was the tail; the tongue was never consumed by larvae and eventually dried up. Large numbers of maggots were noted leaving the carcasses at sites A and B on day 5 and a day later for site C (day 6). On day 4, Chrysomya rufifacies and Chrysomya megacephala visited the carcasses most often. Day 5 was dominated by Chrysomya rufifacies, day 6 by Phormia regina, and the remaining days by Chrysomya rufifacies. Lucilia coeruleiviridis rarely visited the carcasses during this stage.

The last stage noted here was the skeletal remains stage. This stage began approximately on day 10 and continued until the bones were collected on 15 September 2002 (day 41). The flesh of the carcasses was largely consumed by the start of this stage. Adult blow flies rarely visited the carcasses during this stage; therefore, are not depicted in Tables 2-4. Dipterous larvae still present were dominated by the black soldier fly Hermetia illucens (L.) (Diptera: Stratiomyidae).

Lucilia coeruleiviridis showed a high degree of temporal synchrony among the three sites (Table 4). In contrast, Chrysomya rufifacies appeared to be in complete asynchrony among sites with respect to its place in the succession on the alligator carcasses. The remaining three species showed comparison-specific degrees of synchrony/asynchrony among sites. The analysis of variance (Table 5) indicated that only one species, Cochliomyia macellaria, showed a significant difference in relative abundance

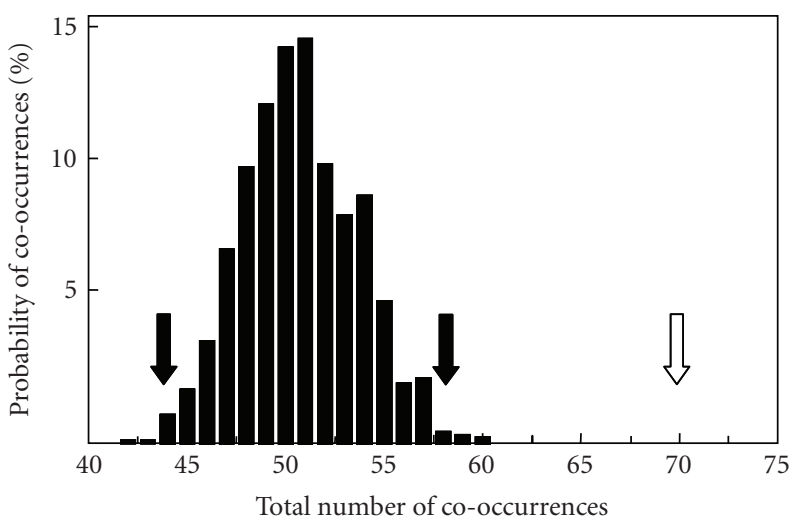

Figure 1: Results of 1000 Monte Carlo simulations for blow fly data collected from fly paper at all three alligator-decay sites. The test statistic for this simulation is the total number of co-occurrences (i.e., the number of times a species occurs on the same day in any pair of sites, summed for all species in the analyses). Closed arrows indicate the critical values at the $95.0 \%$ level. The observed total number of co-occurrences is shown with the open arrow. Probability of co-occurrence is expressed as a percent.

among sites. This species was collected in greater abundance at site A than sites B and C. The Monte Carlo analysis (Figure 1) showed that combined species co-occurrence 
TABLE 4: Dichotomous correlations of blow fly adults over a 10-day period among three sites, each with a single alligator carcass.

\begin{tabular}{|c|c|c|c|}
\hline \multirow{2}{*}{ Species } & \multicolumn{3}{|c|}{ Correlation coefficients } \\
\hline & Site A versus site B & Site A versus site C & Site $B$ versus site $C$ \\
\hline Chrysomya rufifacies & .50 & .272 & .534 \\
\hline Cochliomyia macellaria & $1^{*}$ & .356 & .356 \\
\hline Chrysomya megacephala & .216 & $.802 *$ & 0 \\
\hline Phormia regina & .6 & $.816^{*}$ & .408 \\
\hline Lucilia coeruleiviridis & $.816^{*}$ & $1^{*}$ & $.816^{*}$ \\
\hline
\end{tabular}

* significant at $P<.05$.

TABLE 5: Analysis of variance for five species of blow fly adults over a 10-day period (block) among three sites (main effect), each with a single alligator carcass.

\begin{tabular}{lcccr}
\hline \multirow{2}{*}{ Species } & \multicolumn{3}{c}{ Mean number of blow flies per day \pm SE $\mathrm{a}^{\mathrm{a}}$} & F \\
\hline Chrysomya rufifacies & Site A & Site B & $9.9 \pm 4.3$ & .889 \\
Cochliomyia macellaria & $12.3 \pm 4.0$ & $10.8 \pm 5.5$ & $8.9 \pm 4.0 \mathrm{ab}$ & 0.12 \\
Chrysomya megacephala & $12.7 \pm 3.5 \mathrm{a}$ & $5.5 \pm 2.2 \mathrm{~b}$ & $7.0 \pm 1.9$ & 4.35 \\
Phormia regina & $8.4 \pm 2.1$ & $3.1 \pm 1.9$ & $6.4 \pm 2.8$ & 2.63 \\
Lucilia coeruleiviridis & $4.9 \pm 2.1$ & $3.0 \pm 1.5$ & $8.0 \pm 0.5$ & .030 \\
\hline
\end{tabular}

${ }^{a}$ For significant ANOVA's $(P<.05)$ means with different letters are significantly different at a family error rate of $P=.5$.

occurred at a frequency greater than that expected by a random model. This would indicate at least some synchrony (predictability) of community succession among sites. However, as shown by the correlation analyses, the extent of successional synchrony varied among species and site.

\section{Discussion}

Watson and Carlton $[16,17]$ used alligator carcasses as models to study arthropod succession on carrion in Louisiana. Direct comparisons between our findings and of those made in Louisiana are not possible for several reasons. First, our study was done in the summer, and those of Watson and Carlton $[16,17]$ were done in the spring, fall, and winter. Secondly, the geographical location and vegetation of the sites varied between the studies. Thirdly, the faunal composition of arthropods associated with carrion may be different between the two studies. However, one generalization may be made; Lucilia coeruleiviridis is the first blow fly to arrive at alligator carcasses, and even other carcasses in Louisiana and Alabama. Therefore, this blow fly species may be very important in determining the PMI associated with alligators and possibly other carrion. Lucilia coeruleiviridis is the first blow fly attracted to decaying dogs in Tennessee [9], white-tailed deer and pigs in Louisiana [17], pigs in Florida [11], and on a variety of mammals in northern Mississippi [15]. However, Cochliomyia macellaria is the first to appear on decaying pigs in Texas [31] and in South Carolina [10].

Reasons for the variability of calliphorid succession among our carcasses are unclear, but may be related to subtle differences in the microhabitat in where each carcass was placed or differences in the carcasses themselves. Further attention regarding the floral, chemical, and physical nature of microhabitats needs to be further explored to isolate potential sources of variability in insect succession on carrion. We suspect that the nominal increase in sunlight (lower canopy cover) that site $\mathrm{C}$ received may account for the changes in blow fly succession and physical decay observed at this site.

The variability in insect succession on carrion has been attributed to a multitude of variables. For example, carcass size [32], seasonality $[9,18]$, time since initial exposure of carrion [33], indoors versus outdoors [34], sun versus shade [35], burning [36], burying [37], and hanging [38] have all been investigated. Several studies have evoked the possibility of variation among replicated carcasses, but none of these investigations confirm this suggestion through direct observation (e.g., $[6,13,39,40]$ ). Implicit to all carrion studies is the idea that carcasses (of similar physical dimensions) placed in the same habitat at the same time will exhibit limited differences in the rate of decomposition or succession of insects. Our results indicate that this variability needs to be considered in other model carcasses, such as pigs, a model commonly used to establish baseline forensic data [41]. Although our work needs to be repeated at different times of the year and in different habitats, our results suggest that for any particular vertebrate model, replication is critical.

\section{Acknowledgments}

The authors thank David H. Nelson for providing the alligator carcasses and Charles E. Beard (Clemson University), Kristen D. Cobb (CU), and three anonymous reviewers for making insightful comments on earlier versions of this 
manuscript. Partial funding for this project was received from a grant from the Alabama Center for Estuarine Studies (ACES) awarded to JWM.

\section{References}

[1] E. P. Catts, "Problems in estimating the postmortem interval in death investigations," Journal of Agricultural Entomology, vol. 9, no. 4, pp. 245-255, 1992.

[2] B. Greenberg, "Flies as forensic indicators," Journal of Medical Entomology, vol. 28, no. 5, pp. 565-577, 1991.

[3] J. D. Wells and L. R. LaMotte, "Estimating maggot age from weight using inverse prediction," Journal of Forensic Sciences, vol. 40, no. 4, pp. 585-590, 1995.

[4] A. M. Easton and K. G. Smith, "The entomology of the cadaver," Medicine, Science and the Law, vol. 10, no. 4, pp. 208215, 1970.

[5] C. L. Meek, M. D. Andis, and C. S. Andrews, "Role of the entomologist in forensic pathology, including a selected bibliography," Bibliography of the Entomological Society of America, vol. 1, pp. 1-10, 1983.

[6] G. S. Anderson and S. L. Vanlaerhoven, "Initial studies on insect succession on carrion in southwestern British Columbia," Journal of Forensic Sciences, vol. 41, no. 4, pp. 617 625, 1996

[7] K. Schoenly, M. L. Goff, J. D. Wells, and W. D. Lord, "Quantifying statistical uncertainty in succession-based entomological estimates of the postmortem interval in death scene investigations: a simulation study," American Entomologist, pp. 106-112, 1996.

[8] L. R. LaMotte and J. D. Wells, “p-values for postmortem intervals from arthropod succession data," Journal of Agricultural, Biological, and Environmental Statistics, vol. 5, no. 1, pp. 5868, 2000.

[9] H. B. Reed Jr., "A study of dog carcass communities in Tennessee, with special reference to the insects," The American Midland Naturalist, vol. 59, no. 1, pp. 213-245, 1958.

[10] J. A. Payne, "A summer carrion study of the baby pig Sus scrofa Linnaeus,” Ecology, vol. 46, no. 5, pp. 592-602, 1965.

[11] S. V. Gruner, D. H. Slone, and J. L. Capinera, "Forensically important calliphoridae (Diptera) associated with pig carrion in rural north-central Florida," Journal of Medical Entomology, vol. 44, no. 3, pp. 509-515, 2007.

[12] W. C. Rodriguez and W. M. Bass, "Insect activity and its relationship to decay rates of human cadavers in East Tennessee," Journal of Forensic Sciences, vol. 28, no. 2, pp. 423432, 1983.

[13] J. K. Tomberlin and P. H. Adler, "Seasonal colonization and decomposition of rat carrion in water and on land in an open field in South Carolina," Journal of Medical Entomology, vol. 35, no. 5, pp. 704-709, 1998.

[14] K. A. Kneidel, "Competition and disturbance in communities of carrion-breeding Diptera," Journal of Animal Ecology, vol. 53, no. 3, pp. 849-865, 1984.

[15] J. Goddard and P. K. Lago, "Notes on blow fly (Diptera: Calliphoridae) succession on carrion in northern Mississippi," Journal of Entomological Science, vol. 20, no. 3, pp. 312-317, 1985.

[16] E. J. Watson and C. E. Carlton, "Insect succession and decomposition of wildlife carcasses during fall and winter in Louisiana," Journal of Medical Entomology, vol. 42, no. 2, pp. 193-203, 2005.
[17] E. J. Watson and C. E. Carlton, "Spring succession of necrophilous insects on wildlife carcasses in Louisiana," Journal of Medical Entomology, vol. 40, no. 3, pp. 338-347, 2003.

[18] M. D. Johnson, "Seasonal and microseral variations in the insect populations on carrion," The American Midland Naturalist, vol. 93, no. 1, pp. 79-90, 1975.

[19] W. Johnston and G. Villeneuve, "On the medico-legal applications of entomology," Montreal Medical Journal, vol. 26, pp. 81-90, 1897.

[20] K. Schoenly and W. Reid, "Dynamics of heterotrophic succession in carrion arthropod assemblages: discrete seres or a continuum of change?" Oecologia, vol. 73, no. 2, pp. 192-202, 1987.

[21] D. G. Hall, The Blowflies of North America, The Thomas Say Foundation, Entomological Society of America, Baltimore, Md, USA, 1947.

[22] R. D. Hall and L. H. Townsend Jr., The Insects of Virginia: No.11: The Blow Flies of Virginia (Diptera: Calliphoridae), Research Division Bulletin 123, Virginia Polytechnic Institute and State University, Blacksburg, Va, USA, 1977.

[23] J. P. Dear, "A revision of the new world Chrysomyini (Diptera; Calliphoridae)," Revista Brasileira de Zoologia, vol. 3, pp. 109169, 1985.

[24] T. Whitworth, "Keys to the genera and species of blow flies (Diptera: Calliphoridae) of America north of Mexico," Proceedings of the Entomological Society of Washington, vol. 108, no. 3, pp. 689-725, 2006.

[25] E. P. Catts and N. H. Haskell, Entomology and Death: A Procedural Guide, Joyce's Print Shop, Clemson, SC, USA, 1990.

[26] R. J. Wherry Sr., Contributions to Correlation Analysis, Academic Press, Orlando, Fla, USA, 1984.

[27] J. H. Zar, Biostatistical Analysis, Prentice Hall, Englewood Cliffs, NJ, USA, 3rd edition, 1996.

[28] J. W. Mccreadie, P. H. Adler, and J. F. Burger, "Species assemblages of larval black flies (Diptera:Simuliidae): random or predictable?" Journal of the North American Benthological Society, vol. 16, no. 4, pp. 760-770, 1997.

[29] B. F. J. Manly, Randomization and Monte Carlo Methods in Biology, Chapman and Hall, New York, NY, USA, 1991.

[30] P. H. Crowley, "Resampling methods for computationintensive data analysis in ecology and evolution," Annual Review of Ecology and Systematics, vol. 23, no. 1, pp. 405-447, 1992.

[31] F. M. Tenerio, J. K. Olsen, and C. J. Coates, "Decomposition studies, with a catalog and descriptions of forensically important blow flies (Diptera: Calliphoridae) in central Texas," Southwestern Entomologist, vol. 28, pp. 37-45, 2003.

[32] K. A. Kneidel, "Influence of carcass taxon and size on species composition of carrion-breeding Diptera," American Midland Naturalist, vol. 111, no. 1, pp. 57-63, 1984.

[33] R. D. Hall and K. E. Doisy, "Length of time after death: effect on attraction and oviposition or larviposition of midsummer blow flies (Diptera: Calliphoridae) and flesh flies (Diptera: Sarcophagidae) of medicolegal importance in Missouri," Annals of the Entomological Society of America, vol. 86, no. 5, pp. 589-593, 1993.

[34] M. L. Goff, "Comparison of insect species associated with decomposing remains recovered inside dwellings and outdoors on the island of Oahu, Hawaii," Journal of Forensic Sciences, vol. 36, no. 3, pp. 748-753, 1991. 
[35] B. S. Shean, L. Messinger, and M. Papworth, "Observations of differential decomposition on sun exposed v. shaded pig carrion in coastal Washington state," Journal of Forensic Sciences, vol. 38, no. 4, pp. 938-949, 1993.

[36] F. W. Avila and M. L. Goff, "Arthropod succession patterns onto burnt carrion in two contrasting habitats in the Hawaiian Islands," Journal of Forensic Sciences, vol. 43, no. 3, pp. 581$586,1998$.

[37] S. L. VanLaerhoven and G. S. Anderson, "Insect succession on buried carrion in two biogeoclimatic zones of British Columbia," Journal of Forensic Sciences, vol. 44, no. 1, pp. 3243, 1999.

[38] O. A. Shalaby, L. M. L. DeCarvalho, and M. L. Goff, "Comparison of patterns of decomposition in a hanging carcass and a carcass in contact with soil in a xerophytic habitat on the Island of Oahu, Hawaii," Journal of Forensic Sciences, vol. 45, no. 6, pp. 1267-1273, 2000.

[39] T. I. Tantawi, E. M. El-Kady, B. Greenberg, and H. A. ElGhaffar, "Arthropod succession on exposed rabbit carrion in Alexandria, Egypt," Journal of Medical Entomology, vol. 33, no. 4, pp. 566-580, 1996.

[40] M. S. Archer, "Annual variation in arrival and departure times of carrion insects at carcasses: implications for succession studies in forensic entomology," Australian Journal of Zoology, vol. 51, no. 6, pp. 569-576, 2003.

[41] K. G. Schoenly, N. H. Haskell, and R. D. Hall, "Comparative performance and complementarity of four sampling methods and arthropod preference tests from human and porcine remains at the forensic anthropology center in Knoxville, Tennessee," Journal of Medical Entomology, vol. 44, no. 5, pp. 881-894, 2007. 

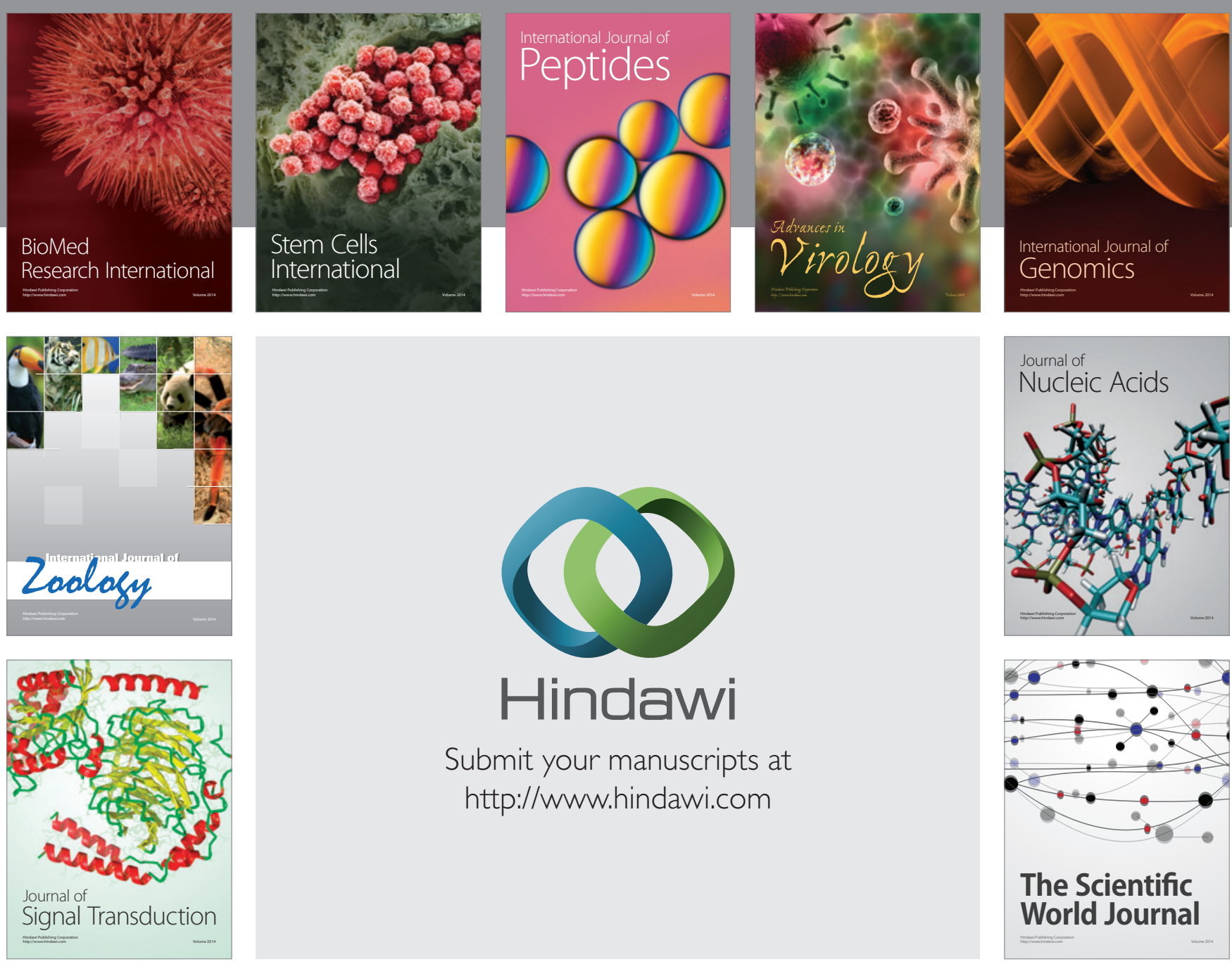

Submit your manuscripts at

http://www.hindawi.com
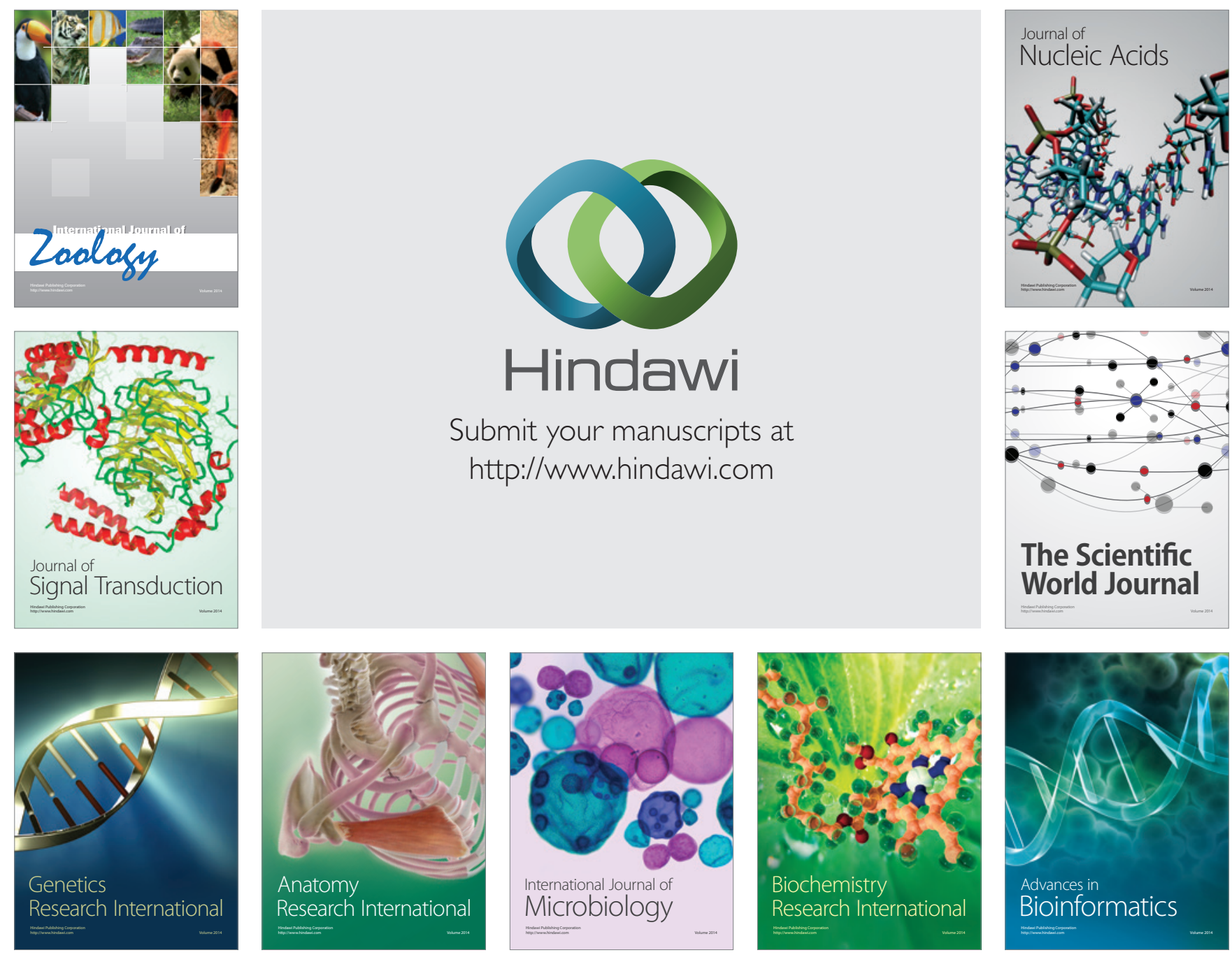

The Scientific World Journal
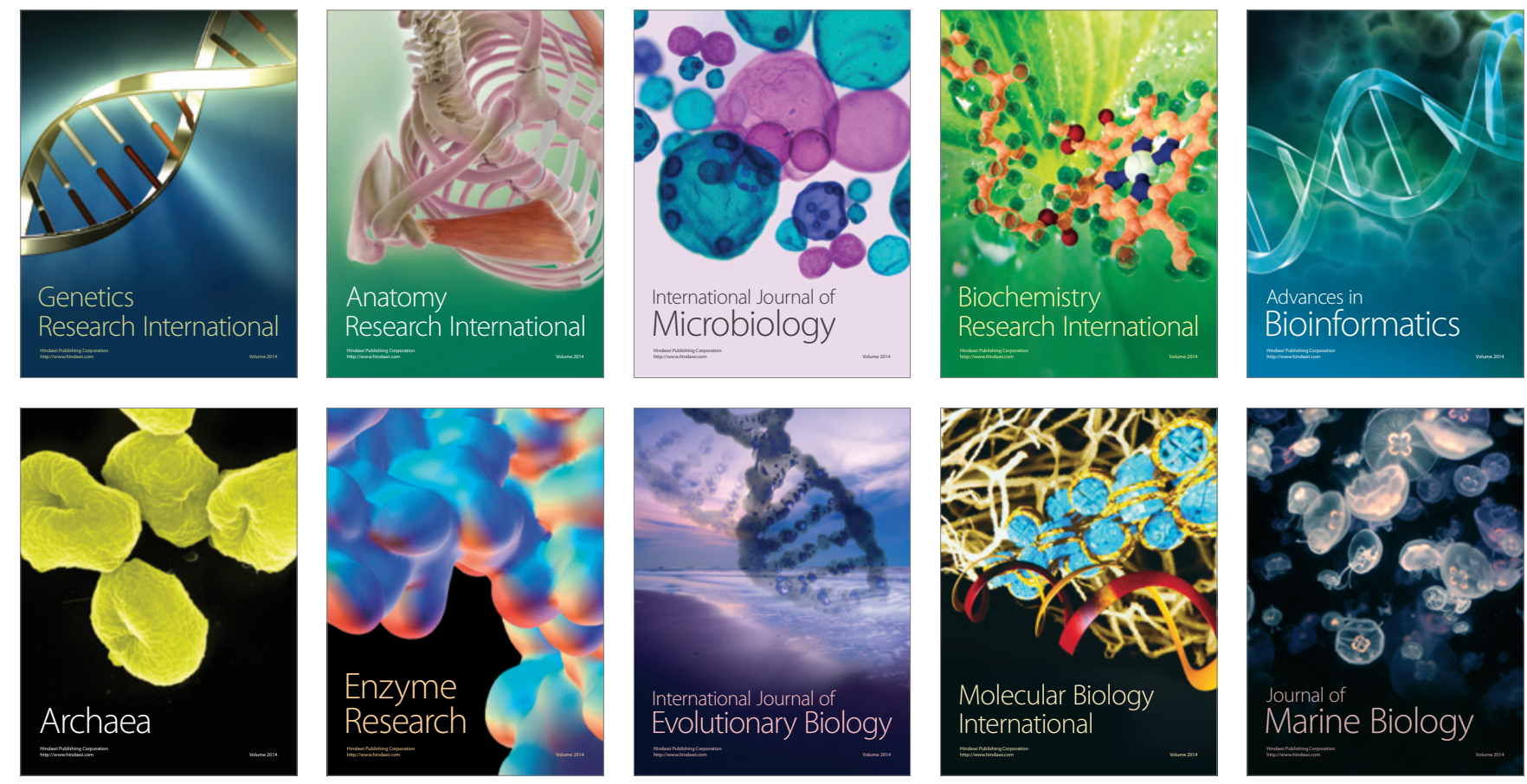